\title{
Opioid modulation of LH secretion during the oestrous cycle of heifers*
}

\author{
R. E. Short $\uparrow$, A. N. Brooks $\ddagger$, A. R. Peters§ and G. E. Lamming \\ AFRC Research Group on Hormones and Farm Animal Reproduction, University of Nottingham, \\ Faculty of Agricultural Science, Sutton Bonington, Loughborough, Leics LE12 5RD, U.K. and \\ $\dagger U S D A$-Agricultural Research Service, Fort Keogh Livestock and Range Research Laboratory, \\ Route 1, Box 2021, Miles City, Montana 59301, U.S.A.
}

\begin{abstract}
Summary. Injections of an opioid agonist (bremazocine) and/or an antagonist (quadazocine) were given to heifers during the luteal or follicular phase of the oestrous cycle. Quadazocine was injected $(210 \mathrm{mg} /$ injection) three times at 2-h intervals, and bremazocine was injected $(0.45 \mathrm{mg} /$ injection) every $15 \mathrm{~min}$ for $6 \mathrm{~h}$. Blood samples were taken every 15 min beginning $6 \mathrm{~h}$ before treatments started and continued for $18 \mathrm{~h}$.

LH secretion patterns were not affected by quadazocine in the luteal-phase heifers, but quadazocine and bremazocine had marked effects during the follicular phase. Quadazocine increased LH secretion by increasing peak height but not peak frequency. Bremazocine decreased LH secretion through both peak height and frequency. This decrease was of greater magnitude than the increase due to quadazocine. When quadazocine and bremazocine were given together, these effects were cancelled and none of the effects carried over into the bleeding period after treatments stopped. No apparent interruption of follicular maturation was detected since all follicular-phase heifers were detected in oestrus at normal intervals. We conclude that heifers in this experiment did not have an opioid-mediated mechanism for progesterone suppression of LH but that an opioid mechanism for modulating LH does exist during the follicular phase.
\end{abstract}

\section{Introduction}

Considerable progress has been made in the understanding of the hypothalamic control of gonadotrophin secretion since Barraclough \& Sawyer (1955) observed that morphine inhibited ovulation in the rat. Packman \& Rothchild (1976) showed that this effect was reversed by naloxone, and Pert \& Snyder (1973) showed that opiate receptors existed in neural tissue. The biological implications of these findings became apparent with the discovery of an endogenous opioid peptide, enkephalin, in the brain (Hughes et al., 1975, 1977). An opioid control mechanism for LH secretion has been implicated in many reproductive states in a wide spectrum of mammals including rats (Bruni $e t$ al., 1977), chimpanzees (Gosselin et al., 1983), monkeys (Ferin et al., 1982), humans (Ropert et al., 1981), pigs (Barb et al., 1985) and sheep (Schanbacher, 1982; Malven et al., 1984; Brooks et al., 1986c), but there have been no reports of work carried out during the oestrous cycle in cattle.

Earlier experiments have largely used pharmacological agents such as naloxone and morphine but more recently other compounds have become available. Bremazocine (Sandoz,

\footnotetext{
*Reprint requests to G. E. Lamming.

$\ddagger$ Present address: The Research Institute, St Joseph’s Hospital, 268 Grosvenor St., London, Ontario, Canada N6A 4V2.

§Present address: Meat and Livestock Commission, PO Box 44, Queensway House, Bletchley, Milton Keynes MK2 2EF, U.K.
} 
Basle, Switzerland) is an opiate agonist with a benzomorphan structure and which inhibits LH secretion (Romer et al., 1980; Marko \& Romer, 1983). Quadazocine (Win 44441-3; Sterling Winthrop, Guildford, Surrey, U.K.) is an opioid antagonist with a similar but more potent activity than naloxone and which stimulates LH secretion (Ward et al., 1983; Brooks et al., 1986a).

The following experiment was conducted to test the possible involvement of endogenous opioids in the control of $\mathrm{LH}$ secretion during the oestrous cycle of heifers. The specific questions were: (1) Will quadazocine increase LH secretion during the luteal and follicular phases of the cycle? (2) Will bremazocine decrease LH secretion during the follicular phase and is this effect reversed by quadazocine?

\section{Materials and Methods}

\section{Animals and management}

The experiment was conducted during January and February 1985 with 36 Hereford $\times$ Friesian heifers (mean weight $349 \pm 4.9 \mathrm{~kg}$ ). They were assigned at random to 6 treatment groups ( 6 per group) and were fed an ad-libitum diet of grass silage and concentrate. The heifers were housed in unheated barns under natural lighting conditions and had free access to water. Oestrous cycles were synchronized by placing a progesterone coil (PRID; Ceva Ltd, Watford, Herts, U.K.) in the vagina for 7 days and injecting $0.5 \mathrm{mg}$ cloprostenol (Estrumate; Coopers Animal Health Ltd, Crewe, U.K.) $24 \mathrm{~h}$ before coil removal. Two groups of heifers were treated on Day $13( \pm 1)$ during the luteal phase of the synchronized cycle. The other 4 groups of heifers were treated during the follicular phase of the synchronized cycle and their entry into the follicular phase was controlled as follows. Coils were inserted on Day $13( \pm 1)$ of the synchronized cycle and removed on Day $17( \pm 1)$ with cloprostenol injected on Day $16( \pm 1)$. Treatments were then started $30-36 \mathrm{~h}$ after coil removal, i.e. on Day 18.

\section{Treatment and blood samples}

Heifers treated during the luteal phase were either controls or treated with quadazocine. The four groups of heifers in the follicular phase were control $(\mathrm{C})$, quadazocine $(\mathrm{Q})$, bremazocine $(\mathrm{B})$ and quadazocine plus bremazocine $(\mathrm{QB})$. Quadazocine $\left[\left(2,6,11 \mathrm{~S}^{*}\right)-(-)-1\right.$-cyclopentyl-5-(1,2,3,4,5,6-hexahydro-8-hydroxy-3,6, 11-trimethyl-2,6-methano-3benzazocin-11-yl)-3-pentone methanesulphonate)] was dissolved in $5 \%$ sterile dextrose $(15 \mathrm{mg} / \mathrm{ml})$ and injected

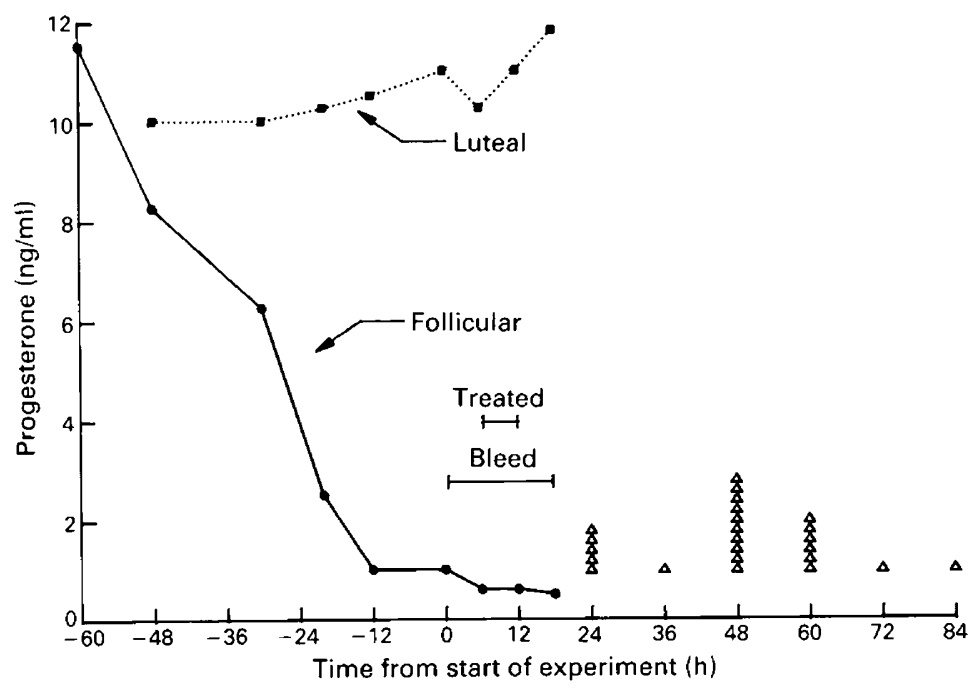

Fig. 1. Changes in progesterone concentrations before and during the experimental period for heifers treated in the follicular or luteal phase of the oestrous cycle. Time of oestrus for each of the follicular-phase heifers is shown $(\triangle)$. 
(210 mg/injection) 3 times at 2 -h intervals. Bremazocine (2-[1-hydroxycyclopropylmethyl]-5-ethyl-9,9-dimethyl2-hydroxy-6,7-benzomorphan) was dissolved in sterile water $(0.15 \mathrm{mg} / \mathrm{ml})$ and injected $(0.45 \mathrm{mg} /$ injection) every 15 $\min$ for $6 \mathrm{~h}$. All injections were given via indwelling jugular cannulae. Blood samples were taken from the same cannulae at 15 -min intervals beginning $6 \mathrm{~h}$ before treatments started and continuing for $18 \mathrm{~h}$. Three 6-h sampling periods were designated as control, treatment and after treatment. Daily blood samples were taken via coccygeal vessel puncture for 5 days before treatments started, to monitor blood progesterone concentrations. Oestrous activity was monitored in follicular heifers for 4 days after the treatment period by observing 4 times per day for mounting activity.

\section{Assays and analyses}

Plasma from blood samples was stored at $-20^{\circ} \mathrm{C}$ until hormone assays were completed. Assays for $\mathrm{LH}$ and progesterone were carried out by the procedures of Webb et al. (1977) and the quality control parameters were similar to those published. Pulses or peaks of LH were defined as any sequence of two or more samples that were elevated above the previous baseline or trough with the highest value being at least $50 \%$ above this baseline.

Statistical analyses were by analysis of variance (AOV) with the four follicular-phase groups being analysed as a $2 \times 2$ factorial to obtain the main effects for quadazocine (Q) and bremazocine (B) treatments as well as their interaction $(\mathrm{Q} \times \mathrm{B})$ (see Steel \& Torrie, 1981). In order to remove inherent differences among heifers, values obtained during the control bleeding period for each individual heifer were subtracted from the treatment and post-treatment values. The changes in $\mathrm{LH}$ for each heifer were designated $\triangle \mathrm{LH}$ and were analysed in a factorial AOV for the treatment and post-treatment periods. For reference, the average values for all heifers obtained during the control period are shown in the figures.

\section{Results}

\section{Luteal phase}

The plasma progesterone concentrations of one heifer remained below $1 \mathrm{ng} / \mathrm{ml}$ during the experimental period, and therefore the data from this animal were excluded from the analysis. The remaining 11 heifers had average progesterone concentrations of $10.9 \pm 1.9 \mathrm{ng} / \mathrm{ml}$ before and during the experimental period (Fig. 1). There was no evidence of any effects of the quadazocine injections on LH secretion as estimated by average concentration $(2 \cdot 1 \pm 0 \cdot 15 \mathrm{ng} / \mathrm{ml})$, frequency of peaks $(2 \cdot 8 \pm 0.35$ peaks $/ 6 \mathrm{~h})$ or average peak height $(3.4 \pm 0 \cdot 19 \mathrm{ng} / \mathrm{ml})$.

\section{Follicular phase}

Average progesterone concentrations for these heifers are shown in Fig. 1. Concentrations decreased rapidly from $11.5 \pm 3.3 \mathrm{ng} / \mathrm{ml}$ before the injection of cloprostenol and removal of the progesterone coil so that values in all heifers were $<1 \mathrm{ng} / \mathrm{ml}$ before the experimental period started. These results plus the fact that there was no evidence of any preovulatory release of LH verify that the experimental period coincided with the follicular phase of the oestrous cycle. Oestrus was observed in all heifers (see Fig. 1) at an average interval of $48 \pm 3 \cdot 2 \mathrm{~h}$ from the start of the experiment. This interval was not affected $(P>0 \cdot 2)$ by any of the treatments.

LH secretion patterns were altered by opioid antagonist and agonist treatments (Fig. 2). For illustration purposes, $\mathrm{LH}$ profiles for representative heifers from each of the four treatment groups (C, Q, B, QB) are shown in Fig. 3.

Injections of quadazocine increased $(P<0.01)$ average $\mathrm{LH}$ concentrations during the treatment period and the effects of bremazocine were just the opposite with a marked decrease $(P<0.01)$. However, there was a significant $(P<0.05)$ interaction between these two treatments due either to the effect of quadazocine being larger when given with bremazocine (QB-B $v s$ Q-C) or the effect of bremazocine being less when given with quadazocine $(\mathrm{QB}-\mathrm{Q}$ vs $\mathrm{B}-\mathrm{C})$. The effect of bremazocine was both more pronounced and more consistent than that of quadazocine. Data for individual heifers showed that 5 of 6 bremazocine-treated heifers had a definite LH response compared to 3 of 6 quadazocine-treated heifers. 


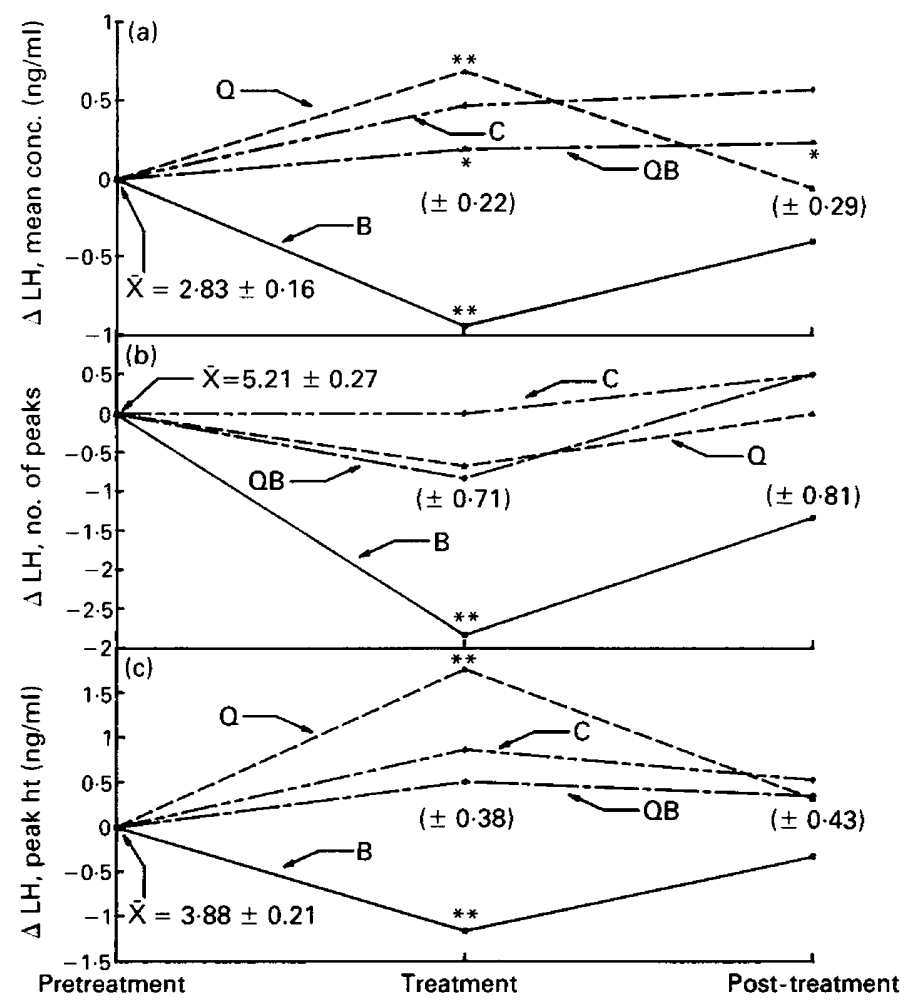

Fig. 2. Effects during the follicular phase of the oestrous cycle of an opioid antagonist, quadazocine $(Q)$, and an agonist, bremazocine $(B)$, as compared to controls $(C)$ and a combined treatment $(\mathrm{QB})$ on changes in $\mathrm{LH}$ secretion $(\Delta \mathrm{LH})$ as measured by $(\mathrm{a})$ average concentration, (b) number of peaks, or (c) peak height during three successive 6-h bleeding periods. Average values (shown as $\overline{\mathbf{x}}$ ) during the control period were subtracted from each period to correct for individual heifer differences. Significant differences from the AOV for the main effects $(Q$ and $\mathrm{B})$ and the interactions $(\mathrm{QB})$ are shown for each period $\left({ }^{*} P<0 \cdot 05 ;{ }^{* *} P<0.01\right)$. Pooled standard errors of the means $( \pm$ s.e.m.) are shown for each period.

There was no significant carryover effect of either treatment into the post-treatment period. However LH concentrations over-compensated after quadazocine-treatment but not after bremazocine (Fig. 2). This difference in response may have been related to the differential magnitude of response to the two drugs during the treatment period.

The increase in LH concentrations due to quadazocine was due to its effect on peak height $(P<0.01)$ and not peak frequency whereas bremazocine affected both height $(P<0.02)$ and frequency $(P<0.01)$. This differential effect resulted in the interaction being significant for frequency of peaks $(P<0.01)$ but not height. For both the peak number and peak height parameters there were no significant carryover effects into the post-treatment period of either quadazocine or bremazocine. These changes in secretion of $\mathrm{LH}$ induced by quadazocine and bremazocine did not change the interval to oestrus (Fig. 1).

\section{Discussion}

The rate of $\mathrm{LH}$ secretion during the luteal phase was low relative to that during the follicular phase as has been shown by Rahe et al. (1980), but this was not reversed by injections of the opioid 
antagonist, quadazocine. Data reported from other species have shown that $\mathrm{LH}$ secretion is increased by opioid antagonists when given during the luteal phase of the oestrous or menstrual cycle or after progesterone injections (Bruni et al., 1977; Quigley \& Yen, 1980; Malven et al., 1984; Brooks et al., 1986b, c). The cow may be different by not having an opioid mediated mechanism for progesterone suppression of $\mathrm{LH}$ secretion or, if that mechanism exists, it may be operating via a different set of receptors. Multiple receptor populations have been shown to be present in other species (Pasternak \& Snyder, 1975; Lord et al., 1977; Chang \& Cuatrecasas, 1979; Kosterlitz et al., 1981; Pasternak et al., 1981). However, a mechanism operating via a different population of receptors is not likely since quadazocine binds to at least three opioid receptors $(\mu, \mathrm{K}$ and $\delta$; Ward et al., 1983).

Our interpretation may be incorrect if for example, a higher dose of antagonist is required during the luteal than in the follicular phase. Such a difference has been proposed by Brooks et al., $1986 \mathrm{c})$. The dose used in this study $(0.60 \mathrm{mg} / \mathrm{kg})$ was higher on a bodyweight basis than doses $(0 \cdot 18$ and $0.36 \mathrm{mg} / \mathrm{kg}$ ) given to sheep and which did produce a response (Brooks et al., 1986a). The dose of quadazocine used in the present study is roughly equivalent to that of naloxone given to sheep, but naloxone has a lower opioid-antagonist potency than quadazocine (Ward et al., 1983). The dose was chosen on the basis of the sheep data (Brooks et al., 1986c). Preliminary data from heifers had indicated that higher doses caused blood haemolysis and minor behavioural changes similar to those observed in sheep (Brooks, 1985).

These data provide evidence that an opioid-mediated mechanism exists for the control of $\mathrm{LH}$ secretion during the follicular phase of the oestrous cycle in heifers. It is likely that the agonist

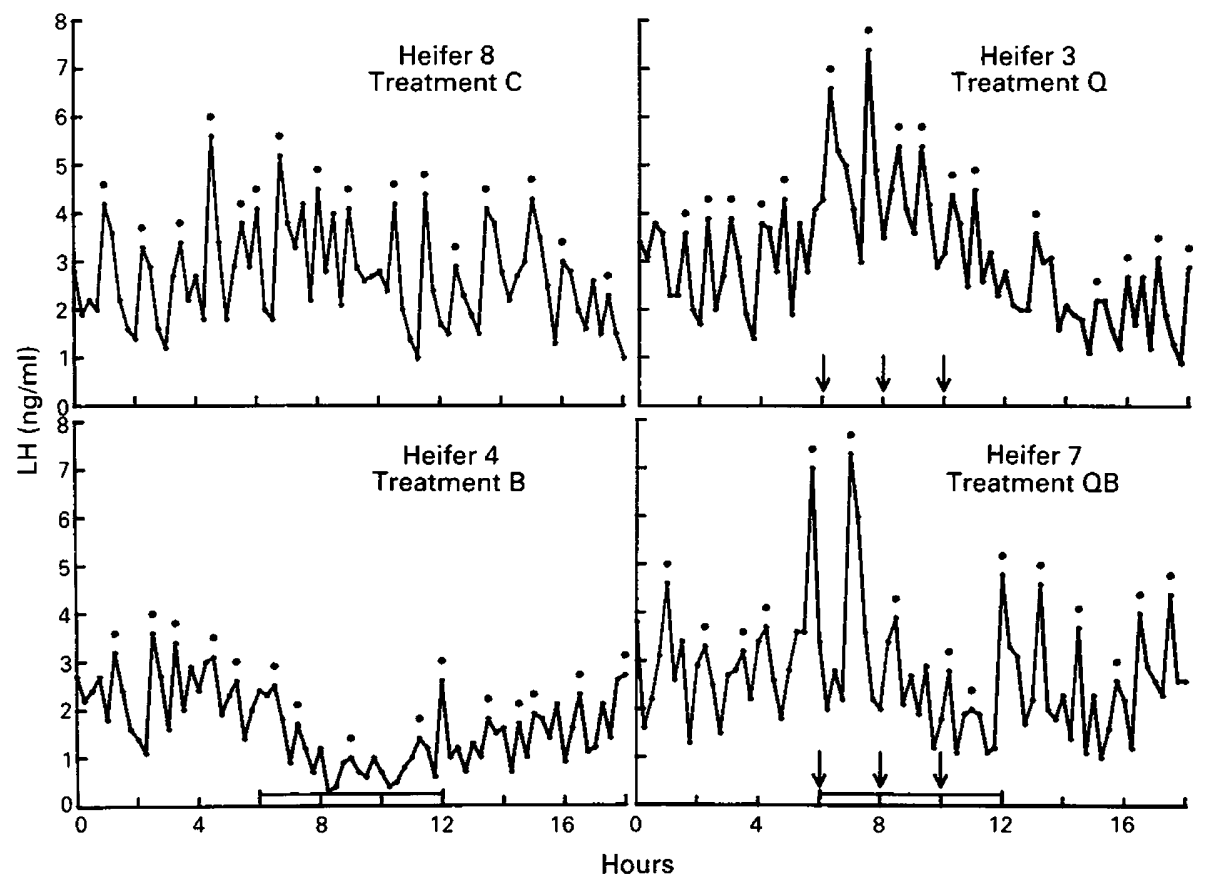

Fig. 3. Luteinizing hormone $(\mathrm{LH})$ profiles for representative heifers during the follicular phase of the oestrous cycle. Treatments are: $\mathrm{C}=$ control; $\mathrm{Q}=$ opioid antagonist, quadazocine injected at times designated by $\downarrow ; \mathrm{B}=$ opioid agonist, bremazocine injected every $15 \mathrm{~min}$ during time designated by horizontal bar; $\mathrm{QB}=$ combined treatment of quadazocine and bremazocine. Defined peaks of $\mathrm{LH}$ are designated by 
and antagonist were binding to the same population of receptors since the effect of each one individually tended to equalise the effect of the other when given together. However, the interaction indicates that this balance was not equal and may be due to differences in relative potencies between the two compounds. Alternatively, since at this stage of the cycle, LH pulse frequency is at or near maximum, bremazocine would have a greater possibility of decreasing LH secretion than quadazocine would have for increasing it. These data agree with those published for the rat (Bruni et al., 1977), human (Quigley \& Yen, 1980), monkey (Ferin et al., 1982), chimpanzee (Gosselin et al., 1983) and sheep (Brooks et al., 1986c), which also show agonist and (or) antagonist effects during this stage of the cycle.

An LH response to opiates was not dependent on the presence of progesterone. However, oestradiol may be involved since women in the early follicular phase do not respond to such drugs whereas women in the late follicular phase do (Quigley \& Yen, 1980). However, anoestrous sheep, which do not respond to antagonist treatments, do not become responsive when given oestrogen alone (Brooks et al., 1986b), a finding which does not support this argument.

The changes in LH secretion induced by quadazocine and bremazocine were not of sufficient magnitude to disturb the follicular maturation process significantly as indicated by normal timing of oestrus after the treatments. Brooks et al. (1986c) found that subsequent preovulatory release of LH and luteal activity were impaired when sheep were treated with the opioid agonist DAMME during the follicular phase. In that study, the suppression of LH secretion was much greater and for a longer period than that observed in this study.

In conclusion, these data provide evidence that an opioid-mediated mechanism exists for the control of LH secretion during the follicular phase of the oestrous cycle of heifers. No evidence was found for a similar mechanism during the luteal phase.

We thank Dr R. Carter, Sterling Winthrop, for donating quadazocine and Dr R. Mauer, Sandoz, for donating bremazocine; The Agricultural and Food Research Council for financial support; Dr L. E. Reichert for LH, the University of Nottingham for the award of a postgraduate scholarship (A.N.B.); and to the Agricultural Research Service, USDA for a research Fellowship (R.E.S.).

Mention of a trade name or specific proprietary products does not constitute a guarantee or warranty by any of the authors involved with this research nor does it imply approval of these products to the exclusion of others.

\section{References}

Barraclough, C.A. \& Sawyer, C.H. (1955) Inhibition of the release of pituitary ovulatory hormones in the rat by morphine. Endocrinology 57, 329-337.

Barb, C.R., Kraeling, R.R., Rampacek, G.B. \& Whisnant, C.S. (1985) Opioid inhibition stimulates luteinizing hormone and prolactin secretion in the gilt. Dom. Anim. Endocr. 2, 93-98.

Brooks, A.N. (1985) Endogenous opioid modulation of luteinizing hormone secretion in the ewe. Ph.D. thesis, University of Nottingham.

Brooks, A.N., Haynes, N.B. \& Lamming, G.E. (1986a) Opioid peptides modulate luteinizing hormone secretion throughout the oestrous cycle in the ewe. $J$. Physiol., Lond. 371, 178 p, Abstr.

Brooks, A.N., Haynes, N.N., Yang, K. \& Lamming, G.E. (1986b) Ovarian steroid involvement in endogenous opioid modulation of $\mathrm{LH}$ secretion in seasonally anoestrous mature ewes. J. Reprod. Fert. 76, 709-715.

Brooks, A.N., Lamming, G.E., Lees, P.D. \& Haynes,
N.B. (1986c) Opioid modulation of LH secretion in the ewe. J. Reprod. Fert. 76, 693-708.

Bruni, J.F., Van Vugt, D., Marshall, S. \& Meites, J. (1977) Effects of naloxone, morphine and methionine enkephalin on serum prolactin, luteinizing hormone, follicle stimulating hormone, thyroid stimulating hormone and growth hormone. Life Sci. 21, 461-466.

Chang, K.J. \& Cuatrecasas, P. (1979) Multiple opiate receptors. J. biol. Chem. 254, 2610-2618.

Ferin, M., Wehrenbergh, W.B., Lam, N.Y., Alston, E.J. \& Vande Wielde, R.L. (1982) Effects and site of action of morphine on gonadotrophin secretion in the female rhesus monkey, Endocrinology 111, 1652-1656.

Gosselin, R.E., Blankstein, J., Dent, D.W., Hobson, W.C., Fuller, G.B., Reyes, F.I., Winter, J.S.D. \& Faiman, C. (1983). Effects of naloxone and an enkephalin analog on serum prolactin, cortisol and gonadotrophins in the chimpanzee. Endocrinology 112, 2168-2173. 
Hughes, J., Smith, T.W., Kosterlitz, H.W., Fothergill, L.A., Morgan, B.A. \& Morris, H.R. (1975) Identification of two related pentapeptides from the brain with potent opiate agonist activity. Nature, Lond. 258, 577-579.

Hughes, J., Kosterlitz, H.W. \& Smith, T.W. (1977) The distribution of methionine-enkephalin and leucineenkephalin in the brain and peripheral tissues. $\mathrm{Br} . J$. Pharmac. 61, 639-647.

Kosterlitz, H.W., Paterson, S.J. \& Robson, L.E. (1981) Characterization of the k-subtype of the opiate receptor in the guinea-pig brain. Br. J. Pharm. 73, 939 949.

Lord, J.A.H., Waterfield, A.A., Hughes, J. \& Kosterlitz, H.W. (1977) Endogenous opioid peptides: multiple agonists and receptors. Nature, Lond. 267, 495-499.

Malven, P.V., Bossut, D.F.B. \& Diekman, M.A. (1984) Effects of naloxone and electroacupuncture treatment on plasma concentrations of LH in sheep. $J$. Endocr. 101, 75-80.

Marko, M. \& Romer, D. (1983) Inhibitory effect of a new opioid agonist on reproductive endocrine activity in rats of both sexes. Life Sci. 33, 233-240.

Packman, P.M. \& Rothchild, J.A. (1976) Morphine inhibition of ovulation: reversal by naloxone. Endocrinology $99,7.10$.

Pasternak, G.W. \& Snyder, S.H. (1975) Identification of novel high affinity opiate receptor binding in rat brain. Nature, Lond. 253, 563-565.

Pasternak, G.W., Caroll-Buatti, M. \& Spiegel, K. (1981) The binding and analgesic properties of a sigma opiate, SFK, 10,047. J. Pharm. exp. Ther. 219, 192-198.
Pert, C.B. \& Snyder, S.H. (1973) Opiate receptor: demonstration in nervous tissue. Science, N.Y. 179, $1011-1014$.

Quigley, M.E. \& Yen, S.S.C. (1980) The role of endogenous opiates on LH secretion during the menstrual cycle. J. clin. Endocr. Metab. 51, 179-181.

Rahe, C.H., Owens, R.E., Fleeger, J.L., Newton, H.J. \& Harms, P.G. (1980) Pattern of plasma luteinizing hormone in the cyclic cow: dependence upon the period of the cycle. Endocrinology 107, 498-503.

Romer, D., Buscher, H., Hill, R.C., Maurer, R., Petcher, T.J., Welle, H.B.A., Bakel, H.C.C.K. \& Akkerman, A.M. (1980) Bremazocine: a potent, long-acting opiate kappa-agonist. Life Sci. 27, 971-978.

Ropert, J.F., Quigley, M.E. \& Yen, S.S.C. (1981) Endogenous opiates modulate pulsatile luteinizing hormone release in humans. $J$. clin. Endocr. Metab. 52, 583-585.

Schanbacher, B.D. (1982) Naloxone provoked LH release in rams, wethers and wethers implanted with testosterone. J. Androl. 3, 31-42.

Steel, R.G.D. \& Torrie, J.H. (1981) Principles and Procedures of Statistics, a Biometrical Approach, 2nd edn. McGraw-Hill, New York.

Ward, S.J., Pierson, A.K. \& Michne, W.F. (1983) Multiple opioid receptor profile in vitro and activity in vivo of the potent opioid antagonist Win 44441-3. Life Sci. 33 (Suppl. 1), 303-306.

Webb, R., Lamming, G.E., Haynes, N.B., Hafs, H.D. \& Manns, J.G. (1977) Response of a cyclic and postpartum cows to injections of synthetic LH-RH. $J$. Reprod. Fert. 50, 203-210.

Received 29 August 1986 